\title{
Lump Sum Contracting Management Mode of Management Synergy Mechanism Model
}

\author{
Huishan $\mathrm{Li}^{1}$, Jie $\mathrm{Ma}^{2}$ \\ ${ }^{1,2}$ School of Civil Engineering, Lanzhou university of technology, Lanzhou 730050, China. \\ majjie0716@163.com
}

Keywords: Synergy, Engineering project, General contracting management, Management synergy mechanism

\begin{abstract}
The management synergy theory in our country had formed a stable theoretical basis after a large number of scholars' research. Lump-sum contracting management model was most widely used in all the other project management modes. In order to further enhance the management efficiency of this model, this paper tried to settle and explore its management form, analyze the problems of lump-sum contracting management mode and the current research status of management synergy theory; then constructed the management synergy mechanism model preliminary. It is necessary to bring the concept of management synergy into general contracting management model, it relieved the contradictions of general contracting management in the management fundamentally, and improved the efficiency of management.
\end{abstract}

\section{Introduction}

The rapid development of infrastructure construction in recent years has promoted the internationalization and unification of modern engineering. The mode of construction projects is increasing, the scale is expanding rapidly, and the demand for resources is also increasing constantly. At present, lump-sum contracting management model has good development prospect and practical basis. However, this kind of rapid application development is not very good play to the advantages of general contracting management, but brings many problems on administration. The form and method of management are traditional, and cannot be well qualified for the requirements of modern engineering project management. It can neither use and save resources reasonably, nor plan and manage team effectively to improve the efficiency of management. Thus derived a new set of project management issues and contradictions. The traditional management, a mode of which was managed and purchased by the owner, and other companies were entrusted to design and construct, was no longer meet the requirements of modern enterprise. In the development of engineering management, it should be fully and effectively synchronized among those administrative staff, and the resource allocation should be used rationally. With the increased scale, in the meanwhile, taking into account the external environment conditions, shortening the construction period, and improving the quality of engineering. Therefore, modern engineering management system is a complicated and open system.

\section{The Development of Management Synergy Theory}

The development and research of synergetic were initially attributed to professor $\mathrm{H} \cdot H a k e^{[1]}$ from the theoretical physics of university of Stuttgart in Germany and professor H•Igor Ansoff ${ }^{[2]}$ who is the Strategic Management scientist in America. $\mathrm{H} \bullet$ Hake studied the synergy theory from the perspective of natural science, especially the laser physics theories, while $\mathrm{H} \cdot$ Igor Ansoff researched from the perspective of economic management and expounded the concept of synergy theory. In the 1970s, $\mathrm{H} \cdot$ Hake tried to make clear to the "synergy"concept and set up a new subject -- "synergetic".

The development of synergetics in China is often applied research on specific issues, then the synergy theory was applied to the management (Enterprise management and project management) to form the concept of management synergy ${ }^{[3]}$. Its main task was to make the management more effectively achieve the overall system structure effects and functional effects, and to improve 
collaborative efficiency of management system. The goal of synergetics was to determine the organization in the science of differ in thousands ways which depended on the law of nature ${ }^{[4]}$. Putting this theory into the management synergy theory which refers to: in a different but overlapping environment (The external environment and internal environment), self-organization of management system form a new operation rule, this rule can be achieved to the synergy effect.

\section{The Necessity of Researching Lump-sum Contracting Management Synergy Mechanism}

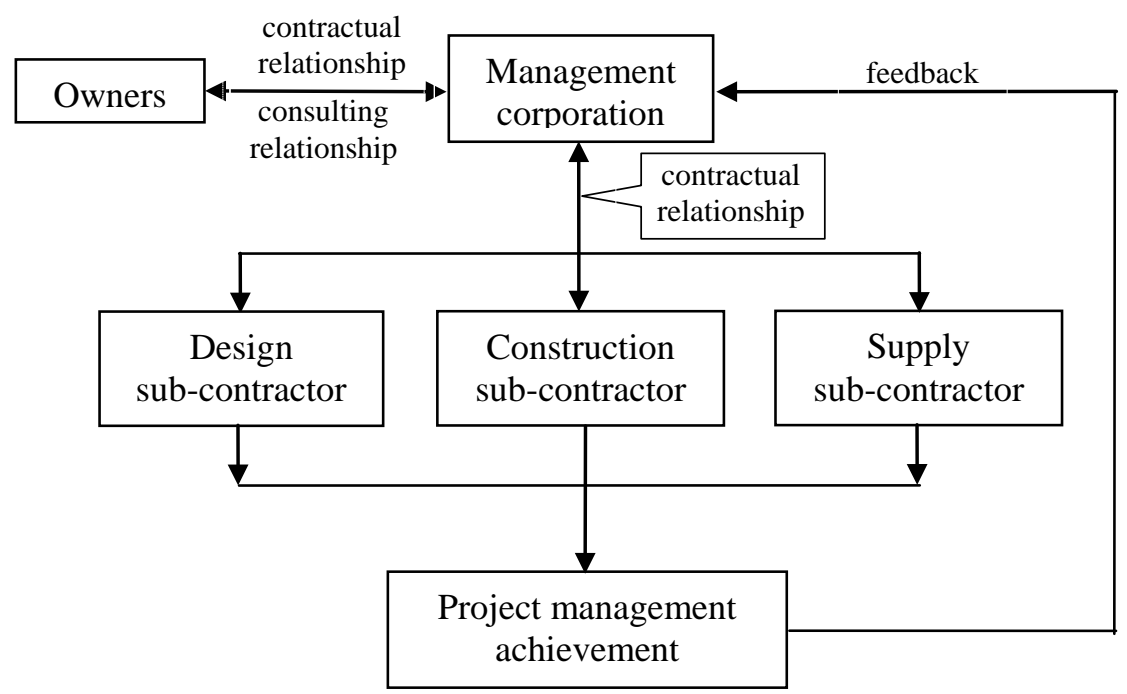

Fig. 1 Lump sum contracting management structure

Lump sum contracting management refers to the owner hires a professional project management team for the management of the whole process of the project, including pre-project planning, feasibility study, design, procurement, construction and other steps in the effective regulation and arrangement ${ }^{[5]}$. Structure is shown in figure 1.

At the end of the 20th century, some outstanding scholars of management industry in our country did lots of in-depth research of management synergy theory and its feasibility, and made three major contents of synergetics can be better applied to the development of the requirements of management theory. At this point, management opened up a new management philosophy, and management efficiency can be promoted to a new height. At the same time, it reflected the necessity and inevitability for the future development of synergy mechanism.

Lump sum contracting is an open and dynamic system. The management of system shows the complexity of its structure and relationships; and it proceeds the ongoing resources and information interaction between different parts and outside world. ${ }^{[6]}$ For Lump sum-contracting management, due to the nature of the whole process management and control of their own, this kind of mode broke the traditional design and construction, completed phase separation. It had good ability on information communication and coordination skills, and it can ensure the fluency of information communication to some extent. These advantages, which are the traditional project management mode can't reach, also laid a good foundation for us to further research the management synergy performance.

\section{The Lump-sum Contracting Management Synergy Mechanism Model}

When the project is in the process of the subcontracting operations, company can optimize the management in parts of "design and construction" in collaborative work, so as to reach the effect like " $1+1>2$ " in the management system. Therefore, the subcontract management of lump-sum contracting management (design and construction) is the key to the management of collaborative optimization.

In the engineering lump-sum contracting management model, the owner entrusted management team on behalf of the owner to manage the whole project, it represented the system-goal of project 
management. Meanwhile, the management object which was adopted by the management synergy theory is organization system. It also has its own target, which is the synergy-goal. Whether the synergy-goal and the system-goal are different or not, is one of the research assumptions ${ }^{[3]}$. Under this assumption, in general contracting management operation system was to build the synergy mechanism in the stage of "design and construction". Although the synergy-goal and the system-goal was consistent in theory; in the actual management situation, it was uncertain that whether the organization system can be completed according to the established goals of project management. There are several unstable and unpredictable factors in the real operation of the system, especially in the stage of design and construction. Therefore, it may create certain gaps between two goals. The management system achieved the optimal synergy when the actual level of organization system and the ideal level of management synergy reach consensus. In practice, however, we cannot present the management synergy perfectly, it can only according to the coordination mechanism model to reach a certain degree of optimization, and then shorten the gap.

\section{Constructing The Lump-sum Contracting Mechanism Model}

According to three mechanisms that were put forward by Liehu Bai based on the analysis of management synergy theory, management synergy mechanism, implementation mechanisms and constraint mechanism ${ }^{[7]}$. Based on these three mechanisms and combined with the preliminary discussion, lump-sum contracting management synergy mechanism model can be set up as shown in figure 2.

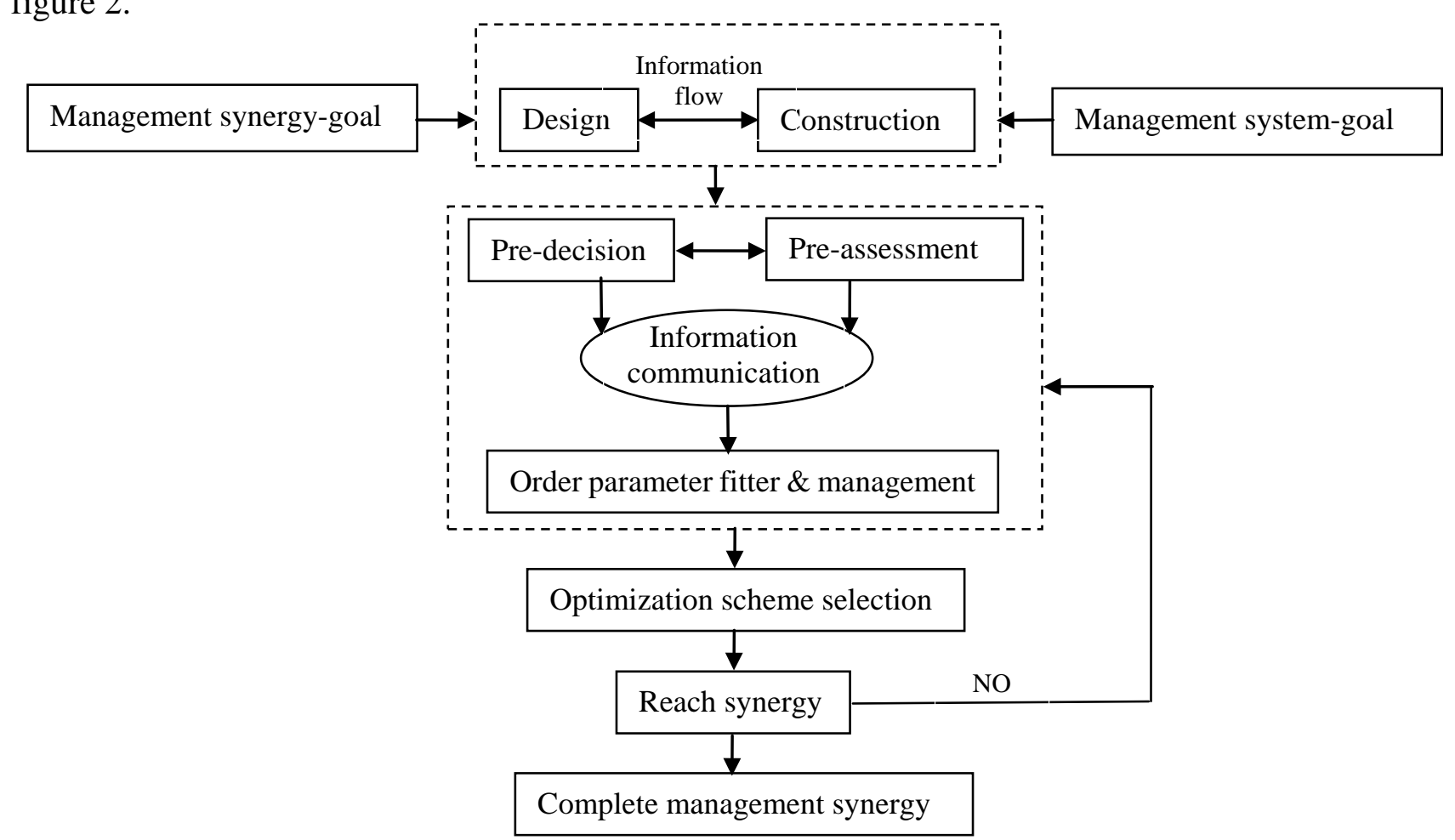

Fig. 2 lump-sum contracting mechanism model

Initially, the collaborative optimization during the subcontract phase of "design and construction" was one of the most direct ways to improve efficiency. It needed to have an optimal selection in advance for sub-contractor, and an evaluation decision scheme in advance. In addition, checking the personal ability and collaborative performance who is working for the sub-contractor. It is worth noticing that pre-decision and pre-assessment was based on the information flow. Timely, effective and accurate information communication can ensure the fine coordination between subsystems, organization system and subsystems, which can also ensure the coordination efficiency in all subcontractors and all project management companies.

Then, under the conditions of good information communication, according to the analysis of the decision scheme and the result of the evaluation, the synergy elements of management organization 
system and its subsystems can be selected. The management of the elements can produce order parameter which grasps the development of organization system, which also has a better understanding of the internal coordination function in general contracting management system. The internal system is divided into fast and slow variables. Under the critical condition of the system, slow variables often determine the core of system qualitative change, while the fast variables do not have profound impact on it. Fast variables obey the slow variables (order parameter), they dominate the behavior of subsystem, and make the system from disorder to order ${ }^{[7]}$. Screening and managing order parameter of “design and construction” phase. Through a variety of management methods and certain organization methods which can control the direction of system development, and then optimize the synergy for management system.

Finally, through the participation of order parameter in the management system, the management system of "design and construction" forms a new organization order. The function of the optimization can help to form in a higher coordination degree. However, information should be collected for the reason that whether optimized management system and scheduled management synergy targets are similar or consistent; if these two are discrepant, it means that pre-decision, pre-evaluation and order parameter does not reach the requirement. In this situation, people need to return to the initial system, and a new collaborative optimization should be carried out. In other words, if teams achieve the established target, it means the management synergy have been completed.

\section{Summary}

According to the construction of management synergy mechanism, order parameter directly dominated the optimization choice of subcontract plan during "design and construction" stage; and then, "optimization scheme selection" became the hardest part to grasp in this system, and the part of which was most easily affected by external factors. Then, the order parameter should be grasped accurately. Using collaborative ideas to optimize the subcontract plan, which should be paid more attention to this point in the future research. At the same time, when the project adopted the general contracting project management mode, management team must pay attention to the information communication and management coordination with the owner, design team, construction team and supervision team. The management synergy theory was combined with general contracting management, in other words, to overcome the oneness of collaboration of the management mode under the general contracting management. It can enhance the engineering quality and efficiency, and achieve the management synergy in the end.

\section{References}

[1] H·Haken. Synergetics [M]. Beijing: Atomic Energy Press. 1984.

[2] H·Igor Ansoff. Corporate Strategy[M]. New York: Mc Graw Hill. 1965.

[3] BAI Liehu, WANG Xiaojun. Construction of Management Synergy Mechanism[J]. Journal of Systems Science. 2009, 17(3): 42-51.

[4] H·Haken. Erfolgsgeheimnisse Der Natur Synergetik: Die Lehre Vom Zusammenwirken Get [M]. Shanghai: Shanghai Translation Press, 2013.

[5] JI Shengping. Intensive Analysis of General Contract Management and Perfection of its Organizational Framework[J]. Building Construction, 2007, 29(1): 74-77.

[6] HE Qinghua, LUO Feng. Large Group Complex Project Management Coordination and Organization Integration[M]. Beijing: Science Press, 2014.

[7] BAI Liehu. Synergetics and Theory of Management Synergy[J]. Gansu Social Science. 2007, 5: 228-230. 